\title{
ChemComm
}

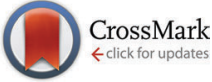

Cite this: Chem. Commun., 2015, 51, 9354

Received 16th February 2015, Accepted 1st May 2015

DOI: $10.1039 / c 5 c c 01462 j$

www.rsc.org/chemcomm

\section{One-pot synthesis of high-performance Co/graphene electrocatalysts for glucose fuel cells free of enzymes and precious metals $\uparrow$}

\author{
Suqin $\mathrm{Ci}^{a}{ }^{a}$ Zhenhai Wen, ${ }^{* a}$ Shun Mao, ${ }^{a}$ Yang Hou, ${ }^{a}$ Shumao Cui, ${ }^{a}$ Zhen $\mathrm{He}^{\mathrm{b}}$ and \\ Junhong Chen*a
}

\begin{abstract}
A facile recipe has been developed to prepare three-dimensional nanoarchitectures of nitrogen-doped graphene loading Co nanoparticle hybrids (Co/NG). The hybrids show an outstanding electrocatalytic activity for glucose oxidation reaction (GOR) and oxygen reduction reaction (ORR), and thus can be used as electrode materials of a nonenzymatic and precious-metal-free glucose fuel cell (GFC).
\end{abstract}

Tremendous strides have been made recently in both fundamental and applied scientific research on graphene and the related hybrids due to their extraordinary electrical, mechanical, and catalytic properties. ${ }^{1}$ A variety of methods, including exfoliation through physical and chemical routes and chemical vapor deposition (CVD), have been developed for production of graphene in recent years. ${ }^{2}$ Among these methods, neither mechanical exfoliation nor the CVD technique is affordable for mass production, and the chemical exfoliation method is a tedious process that includes chemical oxidation, dispersion of graphite, ultrasonic-assisted exfoliation, ion removal, and reduction of graphite oxide. The recently developed method using solid sources is appealing to prepare graphene, whereas a nickel or copper substrate is normally required for the growth of a thin layer of graphene. ${ }^{3}$ On the other hand, graphene nanohybrids are envisioned to improve the functionality of graphene and thus are of great potential for practical applications. Unfortunately, little success has been achieved with the largescale synthesis of graphene while simultaneously implementating the doping of heteroatoms and the incorporation of functional nanostructures on graphene. ${ }^{4}$

Glucose fuel cells (GFCs) have attracted tremendous attention because of their stable and considerable power output through the coupling of the glucose oxidation reaction (GOR) at the anode and the oxygen reduction reaction (ORR) at the cathode. ${ }^{5}$ Adopting an appropriate catalyst is critical for both electrodes due to sluggish

\footnotetext{
${ }^{a}$ Department of Mechanical Engineering, University of Wisconsin-Milwaukee, 3200 North Cramer Street, Milwaukee, WI, 53211, USA.

E-mail:wenzhenhai@yahoo.com, jhchen@uwm.edu

${ }^{b}$ Department of Civil and Environmental Engineering, Virginia Polytechnic Institute and State University, Blacksburg, VA, 24061, USA

$\dagger$ Electronic supplementary information (ESI) available. See DOI: 10.1039/c5cc01462j
}

kinetics and a high overpotential associated with multiple-electron transfer involved in both GOR and ORR. The typical catalysts in a GFC device are enzymes, i.e., glucose oxidase for GOR and laccase for ORR, thanks to their high activity and excellent selectivity. However, the enzymatic glucose fuel cell is susceptible to the operating enviroment and is vulnerable upon long-term running. ${ }^{6}$ Electrocatalysts based on precious metals (e.g., $\mathrm{Pt}, \mathrm{Au}$, or their alloys) could be another option for GFCs due to their considerable activity for GOR and ORR. ${ }^{7}$ Unfortunately, precious metals are subjected to serious poisoning of adsorbed intermediates from the oxidation of glucose, apart from their limited supply and high cost.

In this work, we report a simple one-pot route to prepare graphene nanohybrids through the heat treatment of a solidsource mixture while simultaneously implementing nitrogen doping and loading Co nanoparticles onto graphene (Co/NG). This method breaks through the limitations of traditional methods to prepare hetero-atom-doped graphene hybrids, which normally involve two or more steps, including a complex procedure for preparing graphene, loading functional nanomaterials, and performing the doping process of hetero-atom. Notably, the Co/NG hybrids show outstanding electrocatalytic activity for both GOR and ORR, inspiring us to build a nonenzymatic and precious-metal-free GFC by using the $\mathrm{Co} / \mathrm{NG}$ as catalysts of both the anode and the cathode.

The entire process required only a programmable heattreatment of a solid mixture of $\mathrm{Co}\left(\mathrm{NO}_{3}\right)_{2}$ and cyanamide (ESI, $\dagger$ Fig. S1), during which the cyanamide was decomposed to carbonand nitrogen-rich gases while the $\mathrm{Co}\left(\mathrm{NO}_{3}\right)_{2}$ was reduced to Co nanoparticles, which assisted the growth of NG. The present strategy has the advantages of simple operation, readily accessible raw materials, low cost and high yield. In addition, the N-doping and loading the Co nanoparticles onto graphene were simultaneously implemented in a one-pot reaction, offering an efficient route for functionalizing graphene. Moreover, the present approach can be modified for synthesizing nitrogen-doped graphene after removing Co nanoparticles (Fig. S2, ESI $\dagger$ ).

The scanning electron microscopy (SEM) images of the Co/NG show a large number of particles, ranging from tens to 


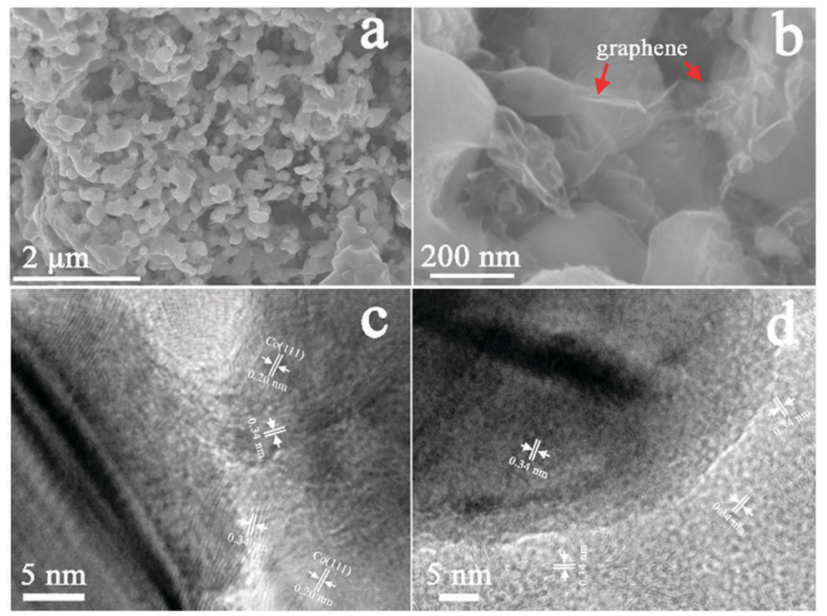

Fig. 1 (a, b) SEM images of the general morphology of the Co/NG and (c, d) TEM images of the Co/NG hybrids from different regions.

hundreds of nanometers, cross-linked together by ultrathin graphene nanosheets, forming a porous three-dimensional (3D) structure (Fig. 1a and b and Fig. S3a-c, ESI $\dagger$ ). The transmission electron microscopy (TEM) images further demonstrate that Co nanoparticles are surrounded and linked together by a large number of graphene sheets that have a well-defined graphite crystalline structure. A close observation indicates that the graphene sheet has 2-10 layers and the Co nanoparticles have a crystalline spacing of ca. $0.2 \mathrm{~nm}$ corresponding to the (111) facet of metallic Co (Fig. 1c and $\mathrm{d}$ and Fig. S3d-f, ESI $\dagger$ ).

Fig. 2a shows the X-ray diffraction (XRD) pattern of the $\mathrm{Co} / \mathrm{NG}$; there are two strong diffraction peaks at $2 \theta=44.2^{\circ}$, $51.5^{\circ}$, which can be well ascribed to the metallic Co (JCPDS No. 47-1049). The absence of a peak associated with graphite is possibly due to the high intensity of Co peaks in the $\mathrm{Co} / \mathrm{NG}$ hybrids. Fig. 2b displays the nitrogen adsorption-desorption isotherm curves, in which a distinct hysteresis loop is observed at the relative pressure $P / P_{0}$ ranging from 0.45 to 1.0 , indicating that the $\mathrm{Co} / \mathrm{NG}$ possesses abundant mesopores and macropores. The Co/NG hybrids have a Brunauer-Emmett-Teller (BET) surface area of $65.1 \mathrm{~m}^{2} \mathrm{~g}^{-1}$ and a pore volume of $0.16 \mathrm{~cm}^{3} \mathrm{~g}^{-1}$. Fig. $2 \mathrm{c}$ presents the survey X-ray photoelectron spectroscopy (XPS) of Co/NG with characteristic spectra of C1s (285.3), N1s (399.6 eV), and Co $2 \mathrm{p}(781.1 \mathrm{eV})$. Further analyses demonstrate that the sample consists of C (59.6 wt\%), N (4.1 wt\%), and Co (36.3 wt\%). The presence of O1s (532.6 eV) most likely results from the adsorbed $\mathrm{O}$ or the substrate. The high-resolution XPS spectra of N1s and Co2p
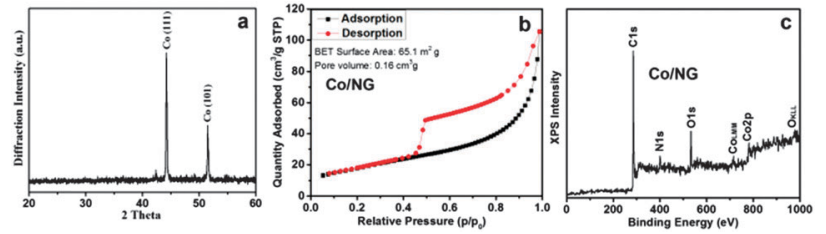

Fig. 2 (a) XRD, (b) nitrogen adsorption/desorption isotherms, and (c) survey XPS of the Co/NG nanohybrids. were further analyzed (Fig. S4, ESI $\dagger$ ). The N1s spectra can be fitted to four different types of $\mathrm{N}$, i.e., pyridine-type $\mathrm{N}(398.2 \mathrm{eV})$, pyrrolictype $\mathrm{N}(399.9 \mathrm{eV})$, graphite-type $\mathrm{N}(401.2 \mathrm{eV})$, and pyridine $\mathrm{N}$-oxide $(402.1 \mathrm{eV})$, indicating varying doping states of $\mathrm{N}$ in the $\mathrm{NG}$ of $\mathrm{Co} / \mathrm{NG}$ nanohybrids. $^{8}$ The appearance of metallic Co $(779.1 \mathrm{eV})$ confirms the existence of metallic Co, while the existence of a high-valence Co species $(781.7 \mathrm{eV})$ is probably derived from partial surface oxidation of metallic Co in air. ${ }^{9}$

Electrochemical tests were first conducted using a threeelectrode system to investigate the electrocatalytic properties of the $\mathrm{Co} / \mathrm{NG}$ for GOR. The cyclic voltammetry (CV) curves of the $\mathrm{Co} / \mathrm{NG}$ in the bulk electrolyte $(0.1 \mathrm{M} \mathrm{NaOH})$ suggest that an oxidation peak is observed at ca. $0.34 \mathrm{~V}$ during the anodic scan, corresponding with the oxidation of metallic cobalt. In the cathodic scan, a slight reduction peak appears at $c a .0 .18 \mathrm{~V}$, implying the partial reduction of high valence of Co compounds. ${ }^{10}$ Both anodic and cathodic peak currents are linearly proportional to the square root of the scan rate (Fig. S5, ESI $\dagger$ ), indicating the $\mathrm{Co} / \mathrm{NG}$ electrode is dominated by a diffusioncontrolled electrochemical process.

We further conducted CV tests on various modified electrodes, including reduced graphene oxide ( $\mathrm{rGO}$ ), $\mathrm{NG}, \mathrm{Co} / \mathrm{NG}$, and $\mathrm{Pt} / \mathrm{C}$, in the absence and presence of $5 \mathrm{mM}$ glucose (Fig. S6, ESI $\dagger$ ). For the $\mathrm{Co} / \mathrm{NG}$ electrode (Fig. S6a, ESI $\dagger$ ), upon the addition of glucose, the anodic current at a potential larger than $0.3 \mathrm{~V}$ increases with a slightly positive shift in peak potential. In contrast, the rGO shows almost no response to glucose (Fig. S6b, ESI $\dagger$ ). The NG shows an observable enhancement in anodic current when adding glucose in the electrolyte (Fig. S6c, ESI $\dagger$ ); nevertheless, the enhancement of current for the NG electrode is much less than that of the $\mathrm{Co} / \mathrm{NG}$ electrode, implying that the NG synergistically work with Co nanoparticles to contribute to the catalysis of GOR. These results highlight that the $\mathrm{Co} / \mathrm{NG}$ plays a significant role in boosting glucose oxidation reaction. Fig. 3a compares the CV response of these electrodes with $5 \mathrm{mM}$ glucose. Obviously, the Co/NG shows a significantly higher current response than the other three electrodes, i.e., the $\mathrm{rGO}$, the $\mathrm{NG}$, and the $\mathrm{Pt} / \mathrm{C}$ electrode, suggesting the $\mathrm{Co} / \mathrm{NG}$ exhibits the best catalytic activity toward the GOR. In addition, the anodic peak current at the $\mathrm{Co} / \mathrm{NG}$ electrode is enhanced correspondingly upon the increase of the glucose concentration (Fig. S7, ESI $\dagger$ ), demonstrating that the $\mathrm{Co} / \mathrm{NG}$ hybrids function as an effective electrocatalyst, boosting the glucose oxidation reaction that is parallel to the oxidation of metallic cobalt. ${ }^{11}$ Chronoamperometry experiments were performed for the $\mathrm{Co} / \mathrm{NG}$ electrode around the peak potential to optimize the operating potential to achieve a higher current response upon successive additions of $10 \mu \mathrm{M}$ glucose (Fig. S8, ESI $\dagger$ ). A higher current response is observed at $0.45 \mathrm{~V}$, which was then selected as the optimum applied potential in the subsequent study. Fig. $3 \mathrm{~b}$ shows the amperometric responses of the $\mathrm{Co} / \mathrm{NG}$ electrode to the successive addition of a certain amount of glucose at $0.45 \mathrm{~V}$; the $\mathrm{Co} / \mathrm{NG}$ electrode shows a linear enhancement in the current response upon adding glucose over a concentration range of $1.67 \mu \mathrm{M}-0.47 \mathrm{mM}$ (Fig. S8b, ESI $\dagger$ ), achieving an sensitivity of up to $4.7 \mathrm{~mA} \mathrm{mM}^{-1} \mathrm{~cm}^{-2}$ with a detection limit of $\sim 0.68 \mu \mathrm{M}$ based on a signal-to-noise ratio of $3(\mathrm{~S} / \mathrm{N})$ for glucose detection. 

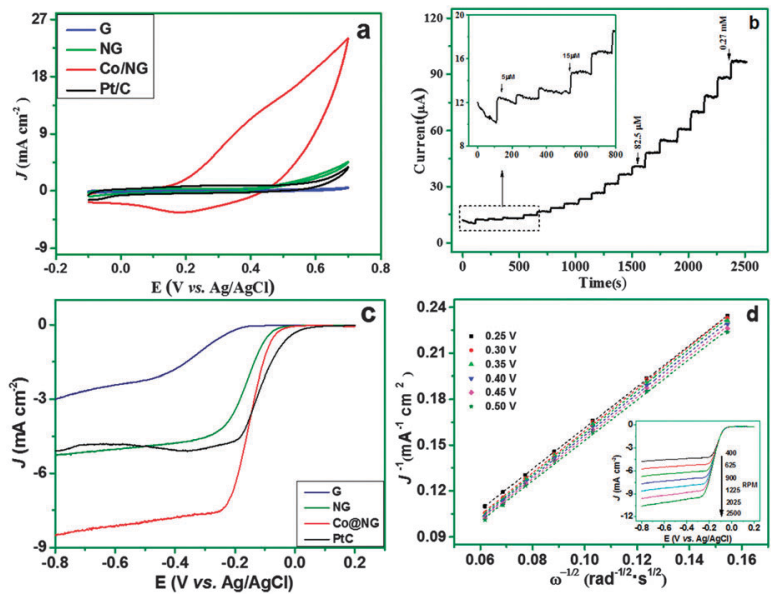

Fig. 3 (a) $\mathrm{CVs}$ of $\mathrm{rGO}, \mathrm{NG}, \mathrm{Co} / \mathrm{NG}$ and $\mathrm{Pt} / \mathrm{C}$ electrodes in $0.1 \mathrm{M} \mathrm{NaOH}$ in the presence of glucose; (b) amperometric response of the Co/NG electrode upon the successive addition of glucose at $0.45 \mathrm{~V}$; (c) rotating disk voltammograms of the $\mathrm{Co} / \mathrm{NG}$ electrode in $\mathrm{O}_{2}$-saturated $0.1 \mathrm{M} \mathrm{NaOH}$ at a scan rate of $5 \mathrm{mV} \mathrm{s}^{-1}$ and $1600 \mathrm{rpm}$; (d) Koutecky-Levich (K-L) plot of current density versus $\omega^{-1 / 2}$ at different potentials on the Co/NG electrode; inset is the polarization curves of ORR at different rorating rates.

The Co/NG also shows excellent electrocatalytic activity toward ORR, the most common reaction occurring in the cathode side for most fuel cells. For comparison, we also performed electrochemical tests in the electrolyte of $0.1 \mathrm{M} \mathrm{NaOH}$ on the $\mathrm{rGO}, \mathrm{NG}, \mathrm{Pt} / \mathrm{C}$, and $\mathrm{Co} / \mathrm{NG}$ electrodes. The $\mathrm{CV}$ results indicate that all electrodes show a well-defined cathodic peak that results from ORR at a different potential in the presence of an $\mathrm{O}_{2}$-saturated electrolyte (Fig. S9, $\mathrm{ESI} \dagger$ ). The $\mathrm{Co} / \mathrm{NG}$ presents a net peak current density (NPCD) of $7.6 \mathrm{~mA} \mathrm{~cm}{ }^{-2}$; this value is higher than those of the $\mathrm{Pt} / \mathrm{C}$ catalyst (6.2 $\left.\mathrm{mA} \mathrm{cm}^{-2}\right)$ and the $\mathrm{NG}\left(5.7 \mathrm{~mA} \mathrm{~cm} \mathrm{~cm}^{-2}\right)$. Fig. 3c shows the ORR polarization curves for these electrodes at a rotation rate of $1600 \mathrm{rpm}$. Consistent with the CV results, the $\mathrm{Co} / \mathrm{NG}$ shows the highest steady-state current density ( $c a .8 .0 \mathrm{~mA} \mathrm{~cm}{ }^{-2}$ ) among all electrodes. In addition, the onset potential of $\mathrm{Co} / \mathrm{NG}$ for the ORR is ca. $-0.01 \mathrm{~V}$, which is slightly lower than that of the $\mathrm{Pt} / \mathrm{C}$ electrode (ca. $0.06 \mathrm{~V})$ but higher than those of NG $(c a-0.03 \mathrm{~V})$ and rGO $(c a .-0.27 \mathrm{~V})$. Given that the NG significantly outperforms the rGO in catalyzing ORR, it is reasonable to conclude that the metallic Co and the doped nitrogen in $\mathrm{Co} / \mathrm{NG}$ together contribute to the enhanced activity for ORR. The Koutecky-Levich (K-L) plots of the $\mathrm{Co} / \mathrm{NG}$ show good linearity between the inverse current density $\left(j^{-1}\right)$ and the inverse of the square root of the rotation speed $\left(\omega^{-1 / 2}\right)$ with parallelism properties at various potentials (Fig. 3d), suggesting first-order reaction kinetics toward the concentration of dissolved $\mathrm{O}_{2}$ and a similar electron-transfer number at different potentials. The electron transfer number $(n)$ of $\mathrm{Co} / \mathrm{NG}$ for catalyzing ORR is calculated to be $c a .3 .8$ in the potential range of -0.25 to $-0.50 \mathrm{~V}$ based on the Koutecky-Levich equation, demonstrating that the ORR dominantly proceeds with a 4-electron pathway on a $\mathrm{Co} / \mathrm{NG}$ electrode, similar to ORR catalyzed by the Pt/C. Some important performance parameters for the ORR on these catalysts are summarized (Table S1, ESI $\dagger$ ), which directly demonstrate the $\mathrm{Co} / \mathrm{NG}$ has comparable catalytic activity with the commercial
Pt/C catalysts. Besides these merits, the Co/NG exhibits stability superior to the $\mathrm{Pt} / \mathrm{C}$ catalyst, as assessed by chronoamperometric measurements (Fig. S10, ESI $\dagger$ ). At a constant voltage of $-0.2 \mathrm{~V}$, the $\mathrm{Co} / \mathrm{NG}$ only shows a negligible decay in the ORR current over $6 \mathrm{~h}$ of continuous operation, whereas the commercial Pt/C catalyst exhibits a $\sim 26 \%$ decrease under the same condition.

The excellent catalytic activity of the $\mathrm{Co} / \mathrm{NG}$ for GOR and ORR implies the feasibility to set up a GFC device using $\mathrm{Co} / \mathrm{NG}$ as both anode and cathode catalysts. An H-type GFC was thus installed to evaluate the performance, as schematically shown in Fig. 4a. The $\mathrm{Co} / \mathrm{NG}$ and the $\mathrm{Pt} / \mathrm{C}$ were investigated by independently operating as both the anode and the cathode of GFC and were denoted as $\mathrm{Co} / \mathrm{NG}_{(\mathrm{a}|| \mathrm{c})^{-}}-\mathrm{GFC}$ and $\mathrm{Pt} / \mathrm{C}_{(\mathrm{a}|| \mathrm{c})^{-}}-\mathrm{GFC}$, respectively. Fig. $4 \mathrm{~b}$ shows the anode and cathode potential recorded with varying current densities for the $\mathrm{Co} / \mathrm{NG}_{(\mathrm{a}|| \mathrm{c})}{ }^{-\mathrm{GFC}}$ and the $\left.\mathrm{Pt} / \mathrm{C}_{(\mathrm{a}|| \mathrm{c})}\right)^{-G F C}$. The $\mathrm{Co} / \mathrm{NG}_{(\mathrm{a}|| \mathrm{c})^{-}}-\mathrm{GFC}$ has a lower anode potential than the $\mathrm{Pt} / \mathrm{C}_{(\mathrm{a}|| \mathrm{c})}-\mathrm{GFC}$ at the same current density, indicating the $\mathrm{Co} / \mathrm{NG}$ has a higher electrocatalytic activity toward GOR than Pt/C. Additionally, the cathode potential remains close for both GFCs, further demonstrating the Co/NG and the Pt/C display comparable catalytic activity for ORR. Electricity generation was monitored using the batch cycle operation at an external resistor of $100 \Omega$. The $\mathrm{Co} / \mathrm{NG}_{(\mathrm{a} \| \mathrm{c})^{-}}$ GFC generates a maximum current density of $0.36 \mathrm{~mA} \mathrm{~cm}-2$ in an electrolyte containing $0.1 \mathrm{M} \mathrm{NaOH}$ and $0.05 \mathrm{M}$ glucose fuel. The generated current then gradually decreased with the color change of the anode electrolyte, from colorless to yellow brown (Fig. S11, ESI $\dagger$ ), indicating glucose prevailingly oxidizes to gluconolactone, providing 2 electrons per mole of glucose (eqn (1)); such catalytic behavior toward glucose oxidation is similar to that of a single enzyme that normally oxidizes glucose to gluconolactone. A reproducible cycle of current is obtained upon 4-cycle operation within about 20 days (Fig. 4c), indicating the $\mathrm{Co} / \mathrm{NG}_{(\mathrm{a} / \mathrm{c})}-\mathrm{GFC}$ is capable of producing steady electricity upon long-term operation. In contrast, the $\mathrm{Pt} / \mathrm{C}_{(\mathrm{a} / \mathrm{c})}-\mathrm{GFC}$
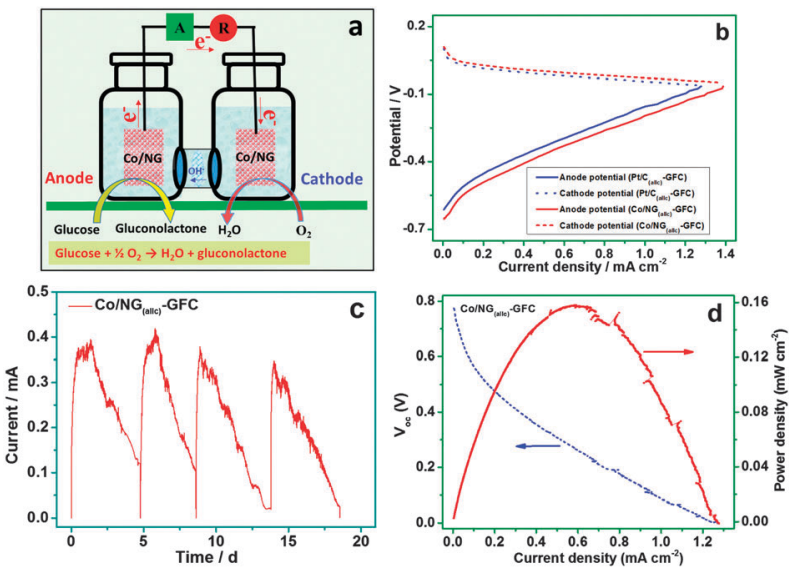

Fig. 4 (a) Schematic diagram of the as-designed $\mathrm{Co} / \mathrm{NG}_{(\mathrm{a} \| \mathrm{lc})}-\mathrm{GFC}$; (b) relation of the current density with the anode and cathode potential of the Co/NG $\mathrm{Na \| c}_{\mathrm{c})}-\mathrm{GFC}$ (red) and $\mathrm{Pt} / \mathrm{C}_{(\mathrm{a} \| \mathrm{c})}-\mathrm{GFC}$ (blue); (c) the output current with time when loading an $R_{\mathrm{ex}}$ of $100 \Omega$ in the Co/NG(allc)-GFC; (d) polarization and power density curves of the $\mathrm{Co} / \mathrm{NG}_{(a \| c)}-\mathrm{GFC}$. 
only produced a maximum current density of $c a .0 .26 \mathrm{~mA} \mathrm{~cm}^{-2}$ in the initial cycle, which is smaller than that of the $\left.\mathrm{Co} / \mathrm{NG}_{(\mathrm{a}|| c)}\right)^{-G F C}$.

$$
\mathrm{C}_{6} \mathrm{H}_{12} \mathrm{O}_{6}+1 / 2 \mathrm{O}_{2} \rightarrow \mathrm{C}_{6} \mathrm{H}_{10} \mathrm{O}_{6}+\mathrm{H}_{2} \mathrm{O}
$$

A polarization curve was also examined to further investigate the performance of the two GFC devices. As shown in Fig. 4d, the $\mathrm{Co} / \mathrm{NG}_{(\mathrm{a}|| \mathrm{c})}-\mathrm{GFC}$ presents an open circuit voltage $\left(V_{\mathrm{oc}}\right)$ of around $0.79 \mathrm{~V}$ and a maximum power density $\left(P_{\max }\right)$ of $0.15 \mathrm{~mW} \mathrm{~cm}^{-2}$ at the current density of $0.6 \mathrm{~mA} \mathrm{~cm}^{-2}$, while the $\left.\mathrm{Pt} / \mathrm{C}_{(\mathrm{a} \| \mathrm{c})}\right)^{-G F C}$ decreases to $0.76 \mathrm{~V}$ in $V_{\mathrm{oc}}$ with a remarkable drop of the $P_{\max }$ to $0.12 \mathrm{~mW} \mathrm{~cm} \mathrm{~cm}^{-2}$ (Fig. S12a, ESI $\dagger$ ). It should be noted

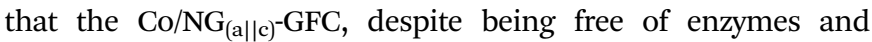
precious metals, yield a considerable maximum current density of $c a .1 .3 \mathrm{~mA} \mathrm{~cm} \mathrm{~cm}^{-2}$, a value comparable with most of the previous enzyme-based fuel cell. ${ }^{12}$ The Co/NG also shows an obvious advantage in durability, as manifested by the cycle tests. The $\mathrm{Pt} / \mathrm{C}_{(\mathrm{a} / \mathrm{c})}-\mathrm{GFC}$ shows a drastic decrease in current density even in the second cycle (Fig. S12b, ESI $\dagger$ ). These results suggest the $\mathrm{Co} / \mathrm{NG}$ hybrids can perform better than the commercial $\mathrm{Pt} / \mathrm{C}$ in terms of output power and stability when used as electrode catalysts of GFCs.

The Co/NG does show the highest catalytic activity, NG displays a rather low activity, and graphene shows the lowest activity toward GOR and ORR (Fig. S6 and S9, ESI $\dagger$ ), suggesting both Co nanoparticles and nitrogen doping synergistically contribute to improving the catalytic activity toward GOR and ORR. On one hand, the Co/NG has a considerably large surface area and a high electrical conductivity; these desirable features can accelerate the electron transfer and facilitate mass (ions or electrolyte) transport. On the other hand, the catalytic sites, including doped nitrogen and Co nanoparticles, can readily access electroactive substances and synergistically catalyze GOR or ORR. Moreover, the Co particles are wrapped and linked by a network of graphene with the formation of a robust hierachical 3D structure, which provides a stable structure for long-term operation of fuel-cell. Given that the $\mathrm{Co} / \mathrm{NG}_{(\mathrm{a}|| c)}-\mathrm{GFC}$ possesses low-cost benefits while outperforming the $\mathrm{Pt} / \mathrm{C}_{(\mathrm{a} \| \mathrm{c})^{-}}$ GFC, the as-developed non-enzymatic and precious-metal free fuel cell is of great potential in energy conversion related fields.

In conclusion, an unprecedented approach has been developed for fabricating graphene-based nanohybrids while simultaneously implementing nitrogen doping and Co nanoparticle loading with solid materials as sources. The Co/NG hybrids show bifunctional electrocatalytic properties towards glucose oxidation reaction and oxygen reduction reaction with a high activity and a low overpotential. The as-designed H-type GFC with the $\mathrm{Co} / \mathrm{NG}$ hybrids as both anode and cathode catalysts significantly outperformed the $\mathrm{Pt} / \mathrm{C}_{(\mathrm{a}|| \mathrm{c})}$-GFC in terms of the output power density and the long-term stability. This pragmatic approach might boost further studies to explore functional graphenebased hybrids for a variety of applications.

\section{Notes and references}

1 (a) D. Li and R. B. Kaner, Science, 2008, 320, 1170; (b) S. Stankovich, D. A. Dikin, G. H. B. Dommett, K. M. Kohlhaas, E. J. Zimney, E. A. Stach, R. D. Piner, S. T. Nguyen and R. S. Ruoff, Nature, 2006, 442, 282; (c) R. Van Noorden, Nature, 2006, 442, 228; (d) J. Baringhaus, M. Ruan, F. Edler, A. Tejeda, M. Sicot, A. TalebIbrahimi, A.-P. Li, Z. Jiang, E. H. Conrad, C. Berger, C. Tegenkamp and W. A. de Heer, Nature, 2014, 506, 349; (e) R. K. Joshi, P. Carbone, F. C. Wang, V. G. Kravets, Y. Su, I. V. Grigorieva, H. A. Wu, A. K. Geim and R. R. Nair, Science, 2014, 343, 752; $(f)$ L. Dai, Acc. Chem. Res., 2013, 46, 31; (g) X.-K. Kong, C.-L. Chen and Q.-W. Chen, Chem. Soc. Rev., 2014, 43, 2841; (h) D. Chen, H. Feng and J. Li, Chem. Rev., 2012, 112, 6027; (i) M. Pumera, Chem. Soc. Rev., 2010, 39, 4146.

2 (a) K. S. Novoselov, Nature, 2014, 505, 291; (b) A. K. Geim, Science, 2009, 324, 1530; (c) C. K. Chua and M. Pumera, Chem. Soc. Rev., 2014, 43, 291; (d) J. N. Coleman, Acc. Chem. Res., 2013, 46, 14; (e) C. N. R. Rao, H. S. S. R. Matte and K. S. Subrahmanyam, Acc. Chem. Res., 2013, 46, 149.

3 (a) Z. Sun, Z. Yan, J. Yao, E. Beitler, Y. Zhu and J. M. Tour, Nature, 2010, 468, 549; (b) X.-H. Li, S. Kurasch, U. Kaiser and M. Antonietti, Angew. Chem., Int. Ed., 2012, 51, 9689; (c) S.-J. Byun, H. Lim, G.-Y. Shin, T.-H. Han, S. H. Oh, J.-H. Ahn, H. C. Choi and T.-W. Lee, J. Phys. Chem. Lett., 2011, 2, 493; (d) G. Ruan, Z. Sun, Z. Peng and J. M. Tour, ACS Nano, 2011, 5, 7601; (e) R. S. Weatherup, C. Baehtz, B. Dlubak, B. C. Bayer, P. R. Kidambi, R. Blume, R. Schloegl and S. Hofmann, Nano Lett., 2013, 13, 4624.

4 (a) X. Wang, Science, 2010, 329, 1467; (b) Y. Zhu, S. Murali, M. D. Stoller, K. J. Ganesh, W. Cai, P. J. Ferreira, A. Pirkle, R. M. Wallace, K. A. Cychosz, M. Thommes, D. Su, E. A. Stach and R. S. Ruoff, Science, 2011, 332, 1537; (c) I. V. Lightcap and P. V. Kamat, Acc. Chem. Res., 2013, 46, 2235; (d) M. Liu, R. Zhang and W. Chen, Chem. Rev., 2014, 114, 5117; (e) X. Huang, X. Qi, F. Boey and H. Zhang, Chem. Soc. Rev., 2012, 41, 666.

5 (a) C. A. Apblett, D. Ingersoll, S. Sarangapani, M. Kelly and P. Atanassov, J. Electrochem. Soc., 2010, 157, B86; (b) D. Basu and S. Basu, Electrochim. Acta, 2011, 56, 6106; (c) S. Kerzenmacher, J. Ducree, R. Zengerle and F. von Stetten, J. Power Sources, 2008, 182, 1.

6 (a) I. Ivanov, T. Vidakovic-Koch and K. Sundmacher, J. Power Sources, 2011, 196, 9260; (b) Z. Zhu, F. Sun, X. Zhang and Y. H. P. Zhang, Biosens. Bioelectron., 2012, 36, 110.

7 (a) D. Basu and S. Basu, Int. J. Hydrogen Energy, 2012, 37, 4678; (b) K. Elouarzaki, A. Le Goff, M. Holzinger, J. Thery and S. Cosnier, J. Am. Chem. Soc., 2012, 134, 14078.

8 (a) D. Usachov, O. Vilkov, A. Grueneis, D. Haberer, A. Fedorov, V. K. Adamchuk, A. B. Preobrajenski, P. Dudin, A. Barinov, M. Oehzelt, C. Laubschat and D. V. Vyalikh, Nano Lett., 2011, 11, 5401; (b) W. Wei, H. Liang, K. Parvez, X. Zhuang, X. Feng and K. Muellen, Angew. Chem., Int. Ed., 2014, 53, 1570; (c) W. Ding, Z. Wei, S. Chen, X. Qi, T. Yang, J. Hu, D. Wang, L.J. Wan, S. F. Alvi and L. Li, Angew. Chem., Int. Ed., 2013, $52,11755$.

9 (a) T. D. M. Elko-Hansen and J. G. Ekerdt, Chem. Mater., 2014, 26, 2642; (b) G. Melaet, W. T. Ralston, C.-S. Li, S. Alayoglu, K. An, N. Musselwhite, B. Kalkan and G. A. Somorjai, J. Am. Chem. Soc., 2014, 136, 2260; (c) D. Banerjee, R. V. Jagadeesh, K. Junge, M.-M. Pohl, J. Radnik, A. Brueckner and M. Beller, Angew. Chem., Int. Ed., 2014, 53, 4359.

10 (a) H. U. Lee, H. Y. Yoo, T. Lkhagvasuren, Y. S. Song, C. Park, J. Kim and S. W. Kim, Biosens. Bioelectron., 2013, 42, 342; (b) K. Elouarzaki, R. Haddad, M. Holzinger, A. Le Goff, J. Thery and S. Cosnier, J. Power Sources, 2014, 255, 24; (c) S. Ci, S. Mao, T. Huang, Z. Wen, D. A. Steeber and J. Chen, Electroanalysis, 2014, 54, 251.

11 (a) L. Wang, Y. Zheng, X. Lu, Z. Li, L. Sun and Y. Song, Sens. Actuators, B, 2014, 195, 1; (b) X.-Y. Lang, H.-Y. Fu, C. Hou, G.-F. Han, P. Yang, Y.-B. Liu and Q. Jiang, Nat. Commun., 2013, 4, 2189.

12 D. Leech, P. Kavanagh and W. Schuhmann, Electrochim. Acta, 2012, 84, 223-234. 